\title{
Do Patients Treated With Dignity Report Higher Satisfaction, Adherence, and Receipt of Preventive Care?
}

Mary Catherine Beach, MD, $M P H^{1,2,3,4}$

Jeremy Sugarman, $M D, M P H, M A^{2,4}$

Rachel L. Jobuson, $M D, P b D^{1,3,5}$

Jose J. Arbelaez, MD, MHS ${ }^{1,2}$

Patrick S. Duggan, $A B^{4}$

Lisa A. Cooper, MD, MPH $H^{1,2,3,6}$

1 Welch Center for Prevention,

Epidemiology, and Clinical Research,

Johns Hopkins University, Baltimore, Md

${ }^{2}$ Division of General Internal Medicine, Department of Medicine, Johns Hopkins University School of Medicine, Baltimore, Md

${ }^{3}$ Department of Health Policy and Management, Johns Hopkins Bloomberg School of Public Health, Baltimore, Md

${ }^{4}$ Phoebe R. Berman Bioethics Institute, Johns Hopkins University, Baltimore, Md

${ }^{5}$ Department of Pediatrics, Johns Hopkins University School of Medicine, Baltimore, Md

${ }^{6}$ National Center for Minority Health and Health Disparities, Johns Hopkins Bloomberg School of Public Health, Baltimore, Md

Conflicts of interest: none reported

\section{CORRESPONDING AUTHOR}

Mary Catherine Beach, MD, MPH Assistant Professor of Medicine and Health Policy and Management Johns Hopkins University School of Medicine

2024 East Monument Street, Suite 2-500

Baltimore, MD 21287

mcbeach@jhmi.edu

\begin{abstract}
PURPOSE Although involving patients in their own health care is known to be associated with improved outcomes, this study was conducted to determine whether respecting persons more broadly, such as treating them with dignity, has additional positive effects.
\end{abstract}

METHODS Using data from the Commonwealth Fund 2001 Health Care Quality Survey of 6,722 adults living in the United States, we performed survey-weighted logistic regression analysis to evaluate independent associations between 2 measures of respect (involvement in decisions and treatment with dignity) and patient outcomes (satisfaction, adherence, and receipt of optimal preventive care). Then we calculated adjusted probabilities of these outcomes and performed stratified analyses to examine results across racial/ethnic groups.

RESULTS After adjustment for respondents' demographic characteristics, the probability of reporting a high level of satisfaction was higher for those treated with dignity vs not treated with dignity $(0.70$ vs $0.38, P<.001)$ and for those involved in, versus not involved in, decisions $(0.70$ vs $0.39, P<.001)$. These associations were consistent across all racial/ethnic groups. Being involved in decisions was significantly associated with adherence for whites, whereas being treated with dignity was significantly associated with adherence for racial/ethnic minorities. The probability of receiving optimal preventive care was marginally greater for those treated with dignity $(0.68$ vs $0.63, P=.054)$, but did not differ with respect to involvement in decisions (0.67 vs $0.67, P=.95)$.

CONCLUSIONS Being treated with dignity and being involved in decisions are independently associated with positive outcomes. Although involving patients in decisions is an important part of respecting patient autonomy, it is also important to respect patients more broadly by treating them with dignity.

Ann Fam Med 2005;3:331-338. DOI: 10.1370/afm.328.

\section{INTRODUCTION}

$\Lambda$ wide body of research provides strong evidence that links patient involvement in care (and physicians' behaviors that facilitate patient involvement in care) to positive outcomes. ${ }^{1-15}$ This literature arguably supports the ethical obligations inherent in the principle of respect for autonomy, a centerpiece of modern bioethics. ${ }^{16}$ The principle of autonomy, however, has been criticized in theory and practice for being excessively individualistic, neglectful of emotion, and legalistic. ${ }^{17-20}$ North American bioethics has also been criticized in general for being dominated by the culture of "whiteness" may be less relevant for some racial/ethnic groups. ${ }^{22,23}$ Furthermore, involving patients in their own medical care, although important, may not fulfill the full spectrum of what the term respect conveys to many people. ${ }^{24}$

There has been considerably less attention paid, among ethicists and 
health services researchers alike, to the broader ethical principle of respect for persons, from which the principle of respect for autonomy is conceptually derived. ${ }^{16,25}$ Respect for persons has been broadly defined as the recognition that all persons have dignity or inherent worth. ${ }^{26}$ Thus, involving patients in decisions (respect for autonomy) is one important, but not exhaustive, expression of respect for persons (Figure 1).

The purpose of this study was to explore the concepts of respect for persons (treatment with dignity) and respect for autonomy (involvement in decisions) and their possible relation to patient outcomes using data from a nationally representative survey. We hypothesized that both being treated with dignity and being involved in decisions would be independently related to positive outcomes, and that being treated with dignity might be more important to racial/ethnic minorities who have had historical or societal experiences of disrespect. ${ }^{27,28}$ Accordingly, the specific aims of this study were (1) to examine the independent contributions of being treated with dignity and being involved in decisions to 3 patient outcomes (satisfaction, adherence, and optimal use of preventive health care), and (2) to examine whether there are differences across racial/ethnic groups in the degree to which being treated with dignity and being involved in decisions are related to positive outcomes.

\section{METHODS}

\section{Study Design and Population}

We used data from the nationally representative Commonwealth Fund 2001 Health Care Quality Survey. ${ }^{29}$ Respondents included 6,722 adults living in the United States who reported their race as black/African American, Asian, Native Hawaiian/Pacific Islander, American Indian/Alaska Native, white, Hispanic/Latino or other/ mixed race. This study included all survey respondents who reported their race as white, African American, Hispanic, or Asian $(n=6,299)$. Respondents who identified themselves as Native Hawaiian/Pacific Islander, American Indian/Alaska Native, or other/mixed race were excluded from this analysis because the numbers of respondents in these categories were too few for meaningful statistical examination.

Random-digit-dialing methods were used to select respondents, and communities with high concentrations of African American, Hispanic and Asian residents were oversampled. As many as 20 repeated telephone call attempts were made to solicit participation in the survey, and an overall response rate of $54.3 \%$ was achieved. Data were weighted to correct for disproportionate sampling and nonresponse and to make final results more reflective of overall population estimates.
Figure 1. Theoretical association between respect for autonomy and respect for persons.

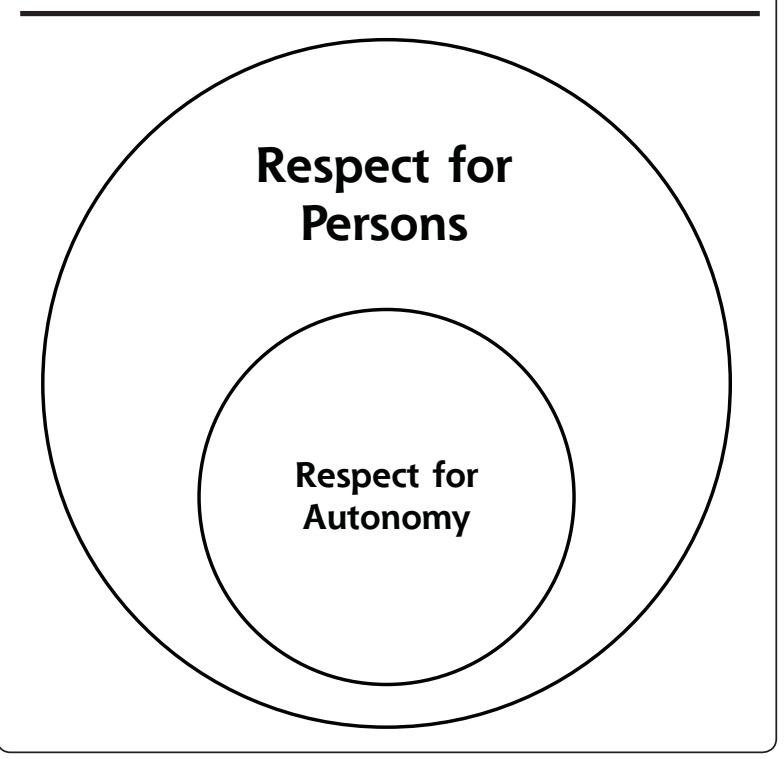

Survey questions covered several domains relating to experiences in the health care system, including usual sources of care and patient-physician communication. In addition, several questions focused on other characteristics of respondents, such as socioeconomic status, self-rated health status, health literacy, primary language spoken in the home, and foreign-born status. The survey was pilot tested, revised, and translated into several languages before final administration. Telephone interviewers who were trained in survey administration offered respondents the option of answering the survey questions in several languages other than English, including Spanish, Mandarin, Cantonese, Vietnamese, and Korean. This study was reviewed and deemed exempt by the Johns Hopkins Institutional Review Board.

\section{Study Variables}

All independent and outcome variables were based on patients' perceptions of their health care, reported in response to a number of multiple-choice questions in the survey. The primary independent variables were 2 items inquiring about different expressions of respect during the patient's last encounter with a doctor: "Did the doctor involve you in decisions about your care (as much as you wanted, almost as much, less than you wanted, a lot less than you wanted)?" and "Did the doctor treat you with (a great deal of) respect and dignity (a fair amount, not too much, none at all)?"

The primary outcome variables were patient satisfaction, adherence, and receipt of optimal preventive services. We measured satisfaction and adherence with single survey items: "Overall, how satisfied or dissatisfied 
are you with the quality of health care you have received during the last 2 years (very satisfied, somewhat satisfied, somewhat dissatisfied, very dissatisfied)?" and "Has there been a time in the past 2 years when you didn't follow a doctor's advice or treatment plan, get a recommended test or see a referred doctor (yes or no)?" We created a dichotomous variable "optimal preventive care" that was a combination of responses to several survey items. Respondents were asked about their receipt of age- and sex-appropriate preventive services: Papanicolau testing within the past 3 years for all women, mammography within the past 2 years for women aged 50 years and older, any history of colorectal screening for all respondents aged 50 years and older, and cholesterol testing within the past 5 years for men aged 35 years and older and for women aged 45 years and older. ${ }^{30}$ For respondents to be classified as receiving optimal preventive care in our analysis, they would need to have had all services for which they were eligible based on age and sex. Men younger than 35 years were excluded from this analysis because there were no items eliciting appropriate preventive services for these respondents.

\section{Statistical Analysis}

We dichotomized the 2 survey items measuring different expressions of respect to compare the highest ranking categories ("being involved in decisions as much as wanted" and "being treated with a great deal of respect and dignity") with other responses, based on the positively skewed distribution of responses. Similarly, based on the positive skew of responses regarding patient satisfaction, we dichotomized this outcome variable to compare the highest ranking category (very satisfied) with all other responses. Patient adherence was naturally dichotomous (possible survey responses were yes or no) and receipt of optimal preventive services was created as a dichotomous variable as described above.

We performed separate logistic regression analyses to evaluate the associations of our 2 different measures of respect with each of our 3 outcome variables individually in both unadjusted and adjusted analyses. To determine the extent to which respect for persons and respect for autonomy were independently associated with the 3 outcomes of interest, we adjusted for both types of respect, and-in the final model-included patient demographic characteristics as covariates. To help identify demographic characteristics that might act as confounders in the relations between our 2 measures of respect and 3 outcomes, we used $\chi^{2}$ tests to compare respondents who reported being involved in decisions and being treated with respect/dignity across age, race/ ethnicity, sex, income, language spoken, education, and insurance categories. Patient demographic characteristics that were significantly $(P<.05)$ related to either independent variable and to at least 1 of the outcome variables were included in the final multivariate models as covariates. Because odds ratios tend to overestimate the probability of frequent events, we present adjusted probabilities for all logistic regression models. These compare respondents treated with different levels of respect while holding all covariates in a given model constant at the mean value (for continuous variables) or the average probability of belonging in a particular category (for dichotomous variables) and thus allow comparisons among otherwise equivalent respondents. ${ }^{31}$

Finally, stratified analyses were performed for each racial/ethnic group separately to explore the degree to which race/ethnicity modifies the relationship of respect with the outcomes of interest. To explore more fully the study hypothesis that respect for persons vs respect for autonomy has different levels of importance for racial/ethnic minorities as compared with whites, post hoc analyses were performed on an aggregate of all racial/ethnic minority respondents to increase statistical power and the ability to detect such differences. To examine whether our findings were influenced by differences across ethnic groups in the interpretation of questions when the survey was administered in different languages, we repeated the stratified analyses limited to respondents who completed the survey questions in English. We conducted all analyses with Stata 7.0 $0^{32}$ using weighted techniques for interpreting survey data.

\section{RESULTS}

\section{Characteristics of Study Sample}

The total study yielded 6,722 responses (54.3\% response rate). Of the 6,722 respondents who participated, we limited our analysis to the 5,514 who reported having had a medical encounter within the past 2 years and who reported their race as white ( $\mathrm{n}$ $=3,150)$, African American $(\mathrm{n}=926)$, Hispanic $(\mathrm{n}$ $=947)$, or Asian $(\mathrm{n}=491)$. Most respondents were female $(65 \%)$, had at least some college education $(62 \%)$, had incomes of more than $200 \%$ of the poverty level (66\%), and spoke English as their primary language $(93 \%)$. Characteristics of the study sample are described in detail elsewhere. ${ }^{29,33,34}$

Overall, 76\% of respondents reported being treated with a great deal of respect and dignity, and $77 \%$ reported being involved in decisions to the extent that they wished. There were no differences in the percentage of respondents reporting either type of respect by sex or education, yet there were differences in reports of involvement in decisions and treatment with dignity across age, race/ethnicity, and income, as shown in Table 1. The Pearson correlation coefficient between treatment with dignity and involvement in decisions 


\begin{tabular}{|c|c|c|c|c|c|}
\hline \multirow[b]{2}{*}{ Characteristic } & \multirow{2}{*}{$\begin{array}{c}\text { Number } \\
\text { (\% of total) }\end{array}$} & \multicolumn{2}{|c|}{$\begin{array}{l}\text { Treated with } \\
\text { Dignity* }\end{array}$} & \multicolumn{2}{|c|}{$\begin{array}{l}\text { Involved in } \\
\text { Decisions }{ }^{\dagger}\end{array}$} \\
\hline & & $\%$ & $P$ Value & $\%$ & $P$ Value \\
\hline \multicolumn{6}{|l|}{ Age, years } \\
\hline 18-39 & $2,394(44)$ & 70 & \multirow{3}{*}{$<.0001$} & 74 & \multirow{3}{*}{.0002} \\
\hline $40-64$ & $2,236(41)$ & 79 & & 77 & \\
\hline$>65$ & $815(15)$ & 85 & & 84 & \\
\hline \multicolumn{6}{|l|}{ Sex } \\
\hline Male & $1,936(35)$ & 75 & \multirow{2}{*}{.2266} & 76 & \multirow{2}{*}{.4005} \\
\hline Female & $3,578(65)$ & 77 & & 78 & \\
\hline \multicolumn{6}{|l|}{ Race/ethnicity } \\
\hline White & $3,150(57)$ & 77 & \multirow{4}{*}{$<.0001$} & 77 & \multirow{4}{*}{$<.0001$} \\
\hline African American & $926(17)$ & 75 & & 75 & \\
\hline Hispanic, Latino & $947(17)$ & 76 & & 67 & \\
\hline Asian & $491(9)$ & 59 & & 59 & \\
\hline \multicolumn{6}{|l|}{ Primary language } \\
\hline English & $5,118(93)$ & 76 & \multirow{2}{*}{.0006} & 78 & \multirow{2}{*}{.0042} \\
\hline Non-English & $396(7)$ & 86 & & 68 & \\
\hline \multicolumn{6}{|l|}{ Income } \\
\hline Below poverty & $592(13)$ & 75 & \multirow{3}{*}{.0032} & 71 & \multirow{3}{*}{.0347} \\
\hline $100 \%-200 \%$ poverty & $936(21)$ & 70 & & 76 & \\
\hline$>200 \%$ poverty & $3,032(66)$ & 78 & & 78 & \\
\hline \multicolumn{6}{|l|}{ Education } \\
\hline High-school incomplete & $660(12)$ & 76 & \multirow{4}{*}{.4485} & 74 & \multirow{4}{*}{.1878} \\
\hline High-school complete & $1,410(26)$ & 74 & & 79 & \\
\hline Some college & $1,480(27)$ & 77 & & 78 & \\
\hline College + & $1,940(35)$ & 78 & & 76 & \\
\hline \multicolumn{6}{|l|}{ Insurance } \\
\hline Uninsured & $695(13)$ & 67 & \multirow{2}{*}{$<.0001$} & 67 & \multirow{2}{*}{$<.0001$} \\
\hline Insured & $4,803(87)$ & 77 & & 79 & \\
\hline
\end{tabular}

In stratified analyses (Table 3 ), being treated with dignity was related to patient satisfaction for all racial/ethnic groups. Being treated with dignity was not associated with adherence for any of the racial/ethnic groups separately, but was associated with adherence for minority respondents together in a combined analysis (data not shown in Table 3: adjusted probability 0.81 if treated with a great deal of dignity vs 0.74 if not treated with a great deal of dignity, $P=$ .041). Being treated with dignity was associated with receipt of optimal preventive care for Latino respondents separately and for all minority groups in a combined analysis (data not shown in Table 3: adjusted probability 0.72 if treated with a great deal of dignity vs 0.63 if not treated with a great deal of dignity, $P=.015$ ).

\section{Involvement in Decisions and Patient Outcomes}

In overall analysis (Table 2), being involved in decisions was associated with patient satisfaction and adherence. It remained independently associated with patient satisfaction and adherence

was 0.361 . Most respondents (62\%) reported both being treated with dignity and being involved in decisions, although there were $12 \%$ who reported being treated with dignity only (without being involved in decisions), $12 \%$ who reported being involved in decisions only (without being treated with dignity), and $14 \%$ who reported neither.

\section{Treatment with Dignity and Patient Outcomes} In the overall analysis (Table 2), respondents who reported being treated with dignity were more likely to report higher levels of satisfaction, adherence to therapy, and receipt of optimal preventive services. The associations between being treated with dignity and all outcomes (satisfaction, adherence, and receipt of optimal preventive care) remained significant after adjustment for being involved in decisions; however, after adjustment for demographic characteristics, only satisfaction remained significantly associated with being treated with dignity. even after adjustment for being treated with dignity and patient demographic covariates. Being involved in decisions was not associated with receipt of optimal preventive care.

In stratified analyses (Table 3 ), being involved in decisions was associated with patient satisfaction for all racial/ethnic groups separately. Being involved in decisions was associated with adherence for white respondents, but not for respondents of any other racial/ethnic group, either separately or combined (data not shown in Table 3: adjusted probability 0.80 for all minority respondents combined if involved in decisions vs 0.77 if not involved in decisions, $P=.412$ ). Finally, being involved in decisions was not associated with receipt of optimal preventive care patients of any race/ ethnicity; however, this association was of borderline statistical significance $(P=.05)$ for Latino respondents, who appeared somewhat more likely to receive optimal preventive services when they reported as much involvement in decision making as they desired. These 


\begin{tabular}{|c|c|c|c|c|c|c|}
\hline \multirow[b]{2}{*}{ Involvement With Health Care } & \multicolumn{2}{|c|}{ Satisfaction } & \multicolumn{2}{|c|}{ Adherence } & \multicolumn{2}{|c|}{ Optimal Preventive Care } \\
\hline & AP $(95 \% \mathrm{Cl})$ & $\begin{array}{c}P \\
\text { Value }\end{array}$ & AP $(95 \% \mathrm{Cl})$ & $\begin{array}{c}P \\
\text { Value }\end{array}$ & AP $(95 \% \mathrm{Cl})$ & $\begin{array}{c}P \\
\text { Value }\end{array}$ \\
\hline \multicolumn{7}{|l|}{ Treated with dignity } \\
\hline \multicolumn{7}{|l|}{ Unadjusted } \\
\hline A great deal & $0.73(0.71-0.75)$ & \multirow{2}{*}{$<.001$} & $0.78(0.76-0.80)$ & \multirow{2}{*}{$<.001$} & $0.66(0.64-0.68)$ & \multirow{2}{*}{.009} \\
\hline Less than a great deal & $0.33(0.29-0.37)$ & & $0.69(0.65-0.72)$ & & $0.60(0.57-0.64)$ & \\
\hline \multicolumn{7}{|l|}{ Adjusted for involvement in decisions } \\
\hline A great deal & $0.71(0.69-0.73)$ & \multirow{2}{*}{$<.001$} & $0.77(0.75-0.79$ & \multirow{2}{*}{.008} & $0.66(0.64-0.68)$ & \multirow{2}{*}{.019} \\
\hline Less than a great deal & $0.38(0.34-0.42)$ & & $0.71(0.69-0.75)$ & & $0.61(0.56-0.65)$ & \\
\hline \multicolumn{7}{|l|}{$\begin{array}{l}\text { Adjusted for demographics* } \\
\text { and involvement in decisions }\end{array}$} \\
\hline A great deal & $0.70(0.68-0.72)$ & \multirow{2}{*}{$<.001$} & $0.77(0.75-0.79$ & \multirow{2}{*}{.096} & $0.68(0.66-0.70)$ & \multirow{2}{*}{.054} \\
\hline Less than a great deal & $0.38(0.34-0.43)$ & & $0.73(0.69-0.77)$ & & $0.63(0.58-0.67$ & \\
\hline \multicolumn{7}{|l|}{ Involved in decisions } \\
\hline \multicolumn{7}{|l|}{ Unadjusted } \\
\hline As much as desired & $0.72(0.70-0.74)$ & \multirow[t]{2}{*}{$<.001$} & $0.78(0.76-0.80)$ & \multirow[t]{2}{*}{$<.001$} & $0.66(0.63-0.68)$ & \multirow[t]{2}{*}{.235} \\
\hline Less than desired & $0.34(0.30-0.38)$ & & $0.67(90.63-0.71)$ & & $0.63(0.59-0.67)$ & \\
\hline \multicolumn{7}{|l|}{ Adjusted for treatment with dignity } \\
\hline As much as desired & $0.70(0.68-0.72)$ & \multirow{2}{*}{$<.001$} & $0.78(0.76-0.79)$ & \multirow{2}{*}{$<.001$} & $0.65(0.63-0.67)$ & \multirow{2}{*}{.841} \\
\hline Less than desired & $0.41(0.36-0.45)$ & & $0.69(0.65-0.72)$ & & $0.64(0.60-0.68)$ & \\
\hline \multicolumn{7}{|l|}{$\begin{array}{l}\text { Adjustment for demographics* } \\
\text { and treatment with dignity }\end{array}$} \\
\hline As much as desired & $0.70(0.68-0.72)$ & \multirow{2}{*}{$<.001$} & $0.78(0.76-0.80)$ & \multirow{2}{*}{$<.001$} & $0.67(0.66-0.70)$ & \multirow{2}{*}{.953} \\
\hline Less than desired & $0.39(0.35-0.44)$ & & $0.69(0.65-0.73)$ & & $0.67(0.62-0.71)$ & \\
\hline
\end{tabular}

findings did not differ when the analysis was limited to respondents across racial/ethnic groups who completed the survey in English.

\section{DISCUSSION}

Patient involvement in care has been associated in previous studies with many positive health outcomes. ${ }^{1-15}$ Our results underscore the important need to go beyond simply involving patients in decisions to respecting persons more broadly by also treating them with dignity. In other words, involving patients in care does not capture the full importance of treating them with dignity, at least insofar as both are associated with positive outcomes.

Perhaps the most interesting finding in this study is the association between treatment with dignity and receipt of optimal preventive care, consistent across all racial/ethnic groups, which is stronger than the association between being involved in decisions and receiving optimal preventive care. It is possible that no association between being involved in decisions and receipt of optimal preventive care was observed because most preventive service recommendations are clear and do not present many options. So, why might being treated with dignity be associated with receipt of optimal preventive care? In contrast to patient adherence (which is a measure of patient behavior), receipt of optimal preventive services requires particular behaviors on the part of both the clinician and the patient- the clinician to recommend the service and the patient to actually have it done. Perhaps patients who are treated with dignity are more likely to pursue recommended interventions. Alternatively, physicians who treat their patients with dignity (that is, those who recognize the inherent value in their patients) might be more likely to ensure that their patients receive optimal preventive services. We do not know from our study whether patients who did not receive optimal preventive care were not prescribed optimal preventive care, or whether they chose not to seek it. Receipt of optimal preventive care was the only quality of care indicator that we evaluated in this study, but it is possible that treatment with dignity is more closely related to quality of care in general than is involvement in decisions. Further research is needed to explore this hypothesis.

It is difficult to interpret these data without wondering what being treated with dignity actually means. Involving patients in decisions may seem fairly straightforward in comparison with the more ambiguous notion of treating patients with dignity. We suggest that treating someone with dignity primarily involves recognizing inherent value in that person. Data from 


\begin{tabular}{|c|c|c|c|c|c|c|}
\hline \multirow[b]{2}{*}{$\begin{array}{l}\text { Involvement With } \\
\text { Health Care }\end{array}$} & \multicolumn{2}{|c|}{ Satisfaction } & \multicolumn{2}{|c|}{ Adherence } & \multicolumn{2}{|c|}{ Optimal Preventive Care } \\
\hline & AP $(95 \% \mathrm{Cl})$ & $\begin{array}{c}P \\
\text { Value }\end{array}$ & AP $(95 \% \mathrm{Cl})$ & $\begin{array}{c}P \\
\text { Value }\end{array}$ & AP $(95 \% \mathrm{Cl})$ & $\begin{array}{c}P \\
\text { Value }\end{array}$ \\
\hline \multicolumn{7}{|l|}{ Treated with dignity* } \\
\hline \multicolumn{7}{|l|}{ Whites $(n=3,488)$} \\
\hline A great deal & $0.71(0.68-0.74)$ & \multirow{2}{*}{$<.001$} & $0.74(0.71-0.77)$ & \multirow{2}{*}{.388} & $0.66(0.61-0.71)$ & \multirow{2}{*}{.367} \\
\hline Less than a great deal & $0.40(0.34-0.47)$ & & $0.71(0.66-0.76)$ & & $0.75(0.56-0.70)$ & \\
\hline \multicolumn{7}{|l|}{$\begin{array}{l}\text { African Americans } \\
(\mathrm{n}=1,037)\end{array}$} \\
\hline A great deal & $0.73(0.67-0.79)$ & \multirow{2}{*}{$<.001$} & $0.79(0.73-0.83)$ & \multirow{2}{*}{.124} & $0.75(0.69-0.80)$ & \multirow{2}{*}{.406} \\
\hline Less than a great deal & $0.35(0.25-0.46)$ & & $0.71(0.61-0.79)$ & & $0.70(0.59-0.79)$ & \\
\hline \multicolumn{7}{|l|}{ Latinos $(n=1,153)$} \\
\hline A great deal & $0.73(0.65-08.80$ & \multirow{2}{*}{.001} & $0.83(0.77-0.87)$ & \multirow{2}{*}{.456} & $0.73(0.66-0.79)$ & \multirow{2}{*}{.039} \\
\hline Less than a great deal & $0.52(0.40-0.63)$ & & $0.79(0.68-0.87)$ & & $0.59(0.47-0.71)$ & \\
\hline \multicolumn{7}{|l|}{ Asians $(n=621)$} \\
\hline A great deal & $0.56(0.45-0.66)$ & \multirow{2}{*}{$<.001$} & $0.80(0.70-0.87)$ & \multirow{2}{*}{.202} & $0.62(0.51-0.71)$ & \multirow{2}{*}{.231} \\
\hline Less than a great deal & $0.18(0.10-0.28)$ & & $0.71(0.58-0.81)$ & & $0.52(0.38-0.66)$ & \\
\hline \multicolumn{7}{|l|}{ Involved in decision ${ }^{\dagger}$} \\
\hline \multicolumn{7}{|l|}{ Whites $(n=3,488)$} \\
\hline As much as desired & $0.71(0.68-0.74)$ & \multirow{2}{*}{$<.001$} & $0.76(0.73-0.79)$ & \multirow{2}{*}{$<.001$} & $0.65(0.60-0.70)$ & \multirow{2}{*}{.481} \\
\hline Less than desired & $0.39(0.33-0.46)$ & & $0.64(0.68-0.69)$ & & $0.67(0.60-0.73)$ & \\
\hline \multicolumn{7}{|l|}{$\begin{array}{l}\text { African Americans } \\
\quad(\mathrm{n}=1,037)\end{array}$} \\
\hline As much as desired & $0.70(0.6400 .76)$ & \multirow{2}{*}{$<.001$} & $0.78(0.72-0.83)$ & \multirow{2}{*}{.433} & $0.74(0.68-0.80)$ & \multirow{2}{*}{.585} \\
\hline Less than desired & $0.44(0.33-0.55)$ & & $0.74(0.64-0.82)$ & & $0.71(0.60-0.80)$ & \\
\hline \multicolumn{7}{|l|}{ Latinos $(n=1,153)$} \\
\hline As much as desired & $0.74(0.67-0.81)$ & \multirow{2}{*}{$<.001$} & $0.82(0.76-0.87)$ & & $0.72(0.66-0.78)$ & \\
\hline Less than desired & $0.46(0.35-0.58)$ & & $0.80(0.70-0.88)$ & .711 & $0.61(0.48-0.72$ & .051 \\
\hline Asians $(n=621)$ & & & & & & \\
\hline As much as desired & $0.50(0.39-0.61)$ & & $0.78(0.68-0.85)$ & & $0.57(0.46-0.67)$ & \\
\hline Less than desired & $0.28(0.17-0.42)$ & .018 & $0.77(0.64-0.86)$ & .876 & $0.65(0.51-0.77)$ & .336 \\
\hline
\end{tabular}

this study, however, do not offer an account of the specific behaviors that are associated with such a valuing. Indeed, the item used in the survey did not specify what being treated with dignity entailed, and so we do not have a clear notion of what respondents were thinking when they answered the question. We suggest that patients are somehow able to determine when clinicians present a valuing attitude, and this perception seems to correlate with important outcomes. These perceptions may correlate with whether the patient was treated kindly or rudely. Further research is needed to understand what clinician behaviors are interpreted by patients as an indication of treatment with dignity.

Finally, our study found that the associations between these 2 forms of respect and most patient outcomes (except patient report of adherence) were consistent across racial/ethnic groups. This aspect of our study provides some input into the question of how respect is conceptualized from the perspectives of patients. ${ }^{21}$ Furthermore, in the case of adherence, our data suggest that being treated with dignity might be more important to racial/ethnic minorities than it is to whites. This finding is important because the modern bioethical concept of respect highlights autonomy, which inadequately captures the notion of dignity. Our data suggest the need to expand the definition of respect, not to negate the importance of respecting autonomy. Our data also suggest that, in future studies, it might be important to measure directly the value that patient's place on the different dimensions of respect for autonomy and respect for persons. Nonetheless, even where our study finds that one of these forms of respect was not associated with positive patient outcomes for a particular racial/ethnic group, we suggest that both forms of respect are owed to all patients on moral grounds alone.

These results have several important implications for practicing clinicians, medical educators, researchers, and medical ethicists. Practicing clinicians ought to consider how to foster their own attitudes of respect- 
fulness toward patients by engaging in self-reflection or participating in educational or training programs in communication skills and professionalism. Medical educators ought to teach students about the principle of respect for autonomy, as well as foster environments in which patients are regarded as valuable and treated with dignity. After all, the most egregious cases of student-reported physician misconduct no longer seem to be in the realm of paternalism, but in the systematic devaluing of patients. ${ }^{35}$ Researchers ought to investigate which behaviors are interpreted by patients as an indication of treatment with dignity and, if our findings are replicated in other studies, to design and evaluate the impact of programs aimed at increasing levels of respect within health care systems.

For ethicists, these data lend support to conceptual arguments for honoring the broader principle of respect for persons that incorporates treating patients with dignity in addition to the narrower responsibility of respecting autonomy. Although respect for persons is conceptualized as the broader principle (Figure 1), our data suggest that patients do not always experience being involved in decisions as an indication of respect more broadly. This finding may be because involving patients in decisions is only one part of respecting autonomy, but it may also be because respect for autonomy is not the full expression of respect, insofar as there are aspects of persons in addition to their autonomy (such as their dignity) that require attention morally.

Our results should be interpreted with several limitations in mind. First, these data are cross-sectional; therefore, causality cannot be attributed to either measure of respect for any of the outcomes. It may be that provision of preventive services, for example, led to increased ratings of respect. Second, the possibility of selection bias exists, because the response rate to the survey was modest (54\%), and we do not have data on nonresponders to assess generalizability. Third, there is the potential for unmeasured confounding with any observational study. For example, it is possible that the associations we observed were related to unmeasured patient, physician, or health care system factors; perhaps the types of health care settings in which one experiences disrespect are the same ones in which there is poor quality of care.

Fourth, there is the possibility of information bias (in respondent recall or reporting), given the time reference for the items: treatment with dignity and involvement in decisions were asked of respondents regarding the last medical encounter, whereas satisfaction, adherence, and optimal preventive care refer to general experiences within the past 2 years. Moreover, we relied on patients' self-report of respect, rather than on an approach of direct observation. Although patients may be best positioned to judge whether they have been treated with respect, it is possible that different racial/ethnic groups attach difference connotations to the terms used in survey items. Insofar as post hoc analyses aimed at distinguishing racial/ethnic minority respondents as an aggregate group from white respondents, such betweengroup differences could also have been underappreciated or overlooked. Although these items did not undergo extensive cognitive testing across languages, it seems unlikely that our findings are simply due to linguistic differences, given that differences across racial/ethnic groups persisted after limiting the analysis to those respondents who completed the survey in English.

Finally, such concepts as respect for persons and respect for autonomy are not perfectly measured by survey items, particularly from single items. Involvement in decisions is one of many ways in which respect for autonomy is expressed. Even so, each of the items used in this study to measure different forms of respect was fairly well representative of the underlying concept involved; thus, the items have face validity. Our study also found that the items possess predictive validity, as shown by their association with important outcomes of interest. Whereas there exist previously validated psychometrically sound instruments to measure involvement in decisions, ${ }^{2,3,36,37}$ no such instrument exists to measure being treated with dignity, despite some preliminary efforts to operationalize the concept. ${ }^{38,39}$ Future research would benefit from well validated measures of different aspects of respect.

In conclusion, being involved in decisions and being treated with dignity are independently important from patients' perspectives. Complete respect is not limited to respect for autonomy; it also entails regarding the patient as having inherent value. Health professionals ought to involve patients in decisions; however, doing so does not replace treating each patient with respect and dignity.

To read or post commentaries in response to this article, see it online at http://www.annfammed.org/cgi/content/full/3/4/331.

Key words: Physician-patient relations/ethics; ethnic groups; personal autonomy; bioethics; respect

Submitted October 7, 2004; submitted, revised, February 24, 2005; accepted March 9, 2005.

These results have been presented in part at the following meetings: Society of General Internal Medicine Annual Meeting, Chicago, III, May 2004; European Association for Communication in Healthcare's (EACH) Meeting, Brugge, Belgium, September 2004; American Society for Bioethics and Humanities' (ASBH) Annual Meeting, Philadelphia, Penn, October 2004.

Funding support: Dr. Beach is a Robert Wood Johnson Generalist Physician Faculty Scholar and a recipient of a K-08 grant from the Agency for Healthcare Research and Quality. Dr. Cooper was supported by a grant from the National Center for Minority Health Disparities (P60MD00214). 
Disclaimer: The views presented here are those of the authors and not necessarily those of the Commonwealth Fund, its directors, officers, or staff.

\section{References}

1. Kaplan SH, Greenfield S, Gandek B, Rogers WH, Ware JE, Jr. Characteristics of physicians with participatory decision-making styles. Ann Intern Med. 1996;124:497-504

2. Brody DS, Miller SM, Lerman CE, Smith DG, Caputo GC. Patient perception of involvement in medical care: relationship to illness attitudes and outcomes. J Gen Intern Med. 1989;4:506-511.

3. Lerman CE, Brody DS, Caputo GC, et al. Patients' Perceived Involvement in Care Scale: relationship to attitudes about illness and medical care. J Gen Intern Med. 1990;5:29-33.

4. Greenfield S, Kaplan S, Ware JE Jr. Expanding patient involvement in care. Effects on patient outcomes. Ann Intern Med. 1985;102:520-528.

5. Wagner EH, Grothaus LC, Sandhu N, et al. Chronic care clinics for diabetes in primary care: a system-wide randomized trial. Diabetes Care. 2001;24:695-700

6. Greenfield S, Kaplan SH, Ware JE Jr, Yano EM, Frank HJ. Patients participation in medical care: effects on blood sugar control and quality of life in diabetes. J Gen Intern Med. 1988;3:448-457.

7. Lorig KR, Sobel DS, Ritter PL, Laurent D, Hobbs M. Effect of a selfmanagement program on patients with chronic disease. Eff Clin Pract. 2001;4:256-262

8. Lorig KR, Ritter P, Stewart AL, et al. Chronic disease self-management program: 2-year health status and health care utilization outcomes. Med Care. 2001;39:1217-1223.

9. Lorig KR, Sobel DS, Stewart AL, et al. Evidence suggesting that a chronic disease self-management program can improve health status while reducing hospitalization: a randomized trial. Med Care. 1999;37:5-14.

10. Kaplan SH, Greenfield S, Ware JE, Jr. Assessing the effects of physician-patient interactions on the outcomes of chronic disease. Med Care. 1989;27:S110-127.

11. Stewart MA. Effective physician-patient communication and health outcomes: a review. CMAJ. 1995;152:1423-1433.

12. Bertakis KD, Roter D, Putnam SM. The relationship of physician medical interview style to patient satisfaction. J Fam Pract. 1991;32:175-181.

13. Roter DL, Stewart M, Putnam SM, et al. Communication patterns of primary care physicians. JAMA. 1997;277:350-356.

14. Levinson W, Roter DL, Mullooly JP, Dull VT, Frankel RM. Physicianpatient communication. The relationship with malpractice claims among primary care physicians and surgeons. JAMA. 1997;277:553559.

15. Hall JA, Roter DL, Katz NR. Meta-analysis of correlates of provider behavior in medical encounters. Med Care. 1988;26:657-675.

16. Beauchamp TL, Childress JF. Principles of Biomedical Ethics. 5th ed. Oxford: Oxford University Press; 2001.

17. Mackenzie C, Stoljar N. Relational Autonomy: Feminist Perspectives on Automony, Agency, and the Social Self. New York, NY: Oxford University Press; 2000.

18. Shannon TA. The Communitarian perspective: autonomy and the common good. In: Grodin MA, ed. Meta Medical Ethics: The Philosophical Foundations of Bioethics. Boston, Mass: Kluwer Academic Publishers; 1995.
19. Halpern J. From Detached Concern to Empathy: Humanizing Medical Practice. Oxford: Oxford University Press; 2001.

20. O'Neill O. Autonomy and Trust in Bioethics. Cambridge: University Press; 2002.

21. Myser C. Differences from somewhere: the normativity of whiteness in bioethics in the United States. Am J Bioeth. 2003;3:1-11.

22. Carrese JA, Rhodes LA. Western bioethics on the Navajo reservation. Benefit or harm? JAMA. 1995;274:826-829.

23. Blackhall LJ, Murphy ST, Frank G, Michel V, Azen S. Ethnicity and attitudes toward patient autonomy. JAMA. 1995;274:820-825.

24. Joffe S, Manocchia M, Weeks JC, Cleary PD. What do patients value in their hospital care? An empirical perspective on autonomy centred bioethics. J Med Ethics. 2003;29:103-108.

25. Lysaught MT. Respect: or, how respect for persons became respect for autonomy. J Med Philos. 2004;29:665-680

26. Kant I. Foundations of the Metaphysics of Morals. 2nd ed. Upper Saddle River, NJ: Prentice-Hall, Inc: 1997.

27. Blanchard J, Lurie N. R-E-S-P-E-C-T: patient reports of disrespect in the health care setting and its impact on care. J Fam Pract. 2004:53:721-730.

28. Byrd WM, Clayton LA. An American Health Dilemma. New York, NY: Routledge; 2000

29. Collins K, Hughes D, Doty M, et al. Diverse Communities, Common Concerns: Assessing Health Care Quality for Minority Americans. New York, NY: The Commonwealth Fund; 2002.

30. U.S. Preventive Services Task Force. Guide to Clinical Preventive Services: Report of the U.S. Preventive Services Task Force. Baltimore, MD: Williams \& Wilkins; 1996.

31. McNutt LA, Wu C, Xue X, Hafner JP. Estimating the relative risk in cohort studies and clinical trials of common outcomes. Am J Epidemiol. 2003; 157:940-943.

32. Stata Statistical Software. College Station, Tex: Stata Corporation; 2001.

33. Saha S, Arbelaez JJ, Cooper LA. Patient-physician relationships and racial disparities in the quality of health care. Am J Public Health. 2003;93:1713-1719.

34. Johnson RL, Saha S, Arbelaez JJ, Beach MC, Cooper LA. How do patients perceptions of their medical care relate to theoretical constructs of cultural competence? J Gen Intern Med. 2003;18:177.

35. Kushner T, Thomasma D, eds. Ward Ethics: Dilemmas for Medical Students and Doctors in Training. New York, NY: Cambridge University Press; 2001.

36. Kaplan SH, Gandek B, Greenfield S, Rogers W, Ware JE. Patient and visit characteristics related to physicians' participatory decisionmaking style. Results from the Medical Outcomes Study. Med Care. 1995:33:1176-1187.

37. Ende J, Kazis L, Ash A, Moskowitz MA. Measuring patients' desire for autonomy: decision making and information-seeking preferences among medical patients. J Gen Intern Med. 1989;4:23-30.

38. Chochinov HM. Dignity-conserving care--a new model for palliative care: helping the patient feel valued. JAMA. 2002;287:2253-2260.

39. Chochinov HM, Hack T, McClement S, Kristjanson L, Harlos M Dignity in the terminally ill: a developing empirical model. Soc Sci Med. 2002;54:433. 